\title{
Effect of River Indus Sand and Recycled Concrete Aggregates as Fine and Coarse Replacement on Properties of Concrete
}

\author{
Abdul Razzaque Sandhu \\ Department of Civil Engineering, \\ Mehran University of Engineering and \\ Technology, Shaheed Zulfiqar Ali Bhutto \\ Campus, Khairpur Mirs, Pakistan \\ abdulrazzaque@muetkhp.edu.pk
}

\section{Hemu Karira}

Department of Civil Engineering, Mehran University of Engineering and Technology, Shaheed Zulfiqar Ali Bhutto Campus, Khairpur Mirs, Pakistan engr.hemu07civil@gmail.com

\author{
Muhammad Tahir Lakhiar \\ Faculty of Civil and Environmental \\ Engineering, Universiti Tun Hussein Onn \\ Malaysia, 86400 Parit Raja, Batu Pahat, \\ Malaysia \\ mtl.eng17@gmail.com
}

\author{
Ashfaque Ahmed Jhatial \\ Department of Civil Engineering, \\ Mehran University of Engineering and \\ Technology, Shaheed Zulfiqar Ali Bhutto \\ Campus, Khairpur Mirs, Pakistan \\ ashfaqueahmed@muetkhp.edu.pk
}

\author{
Qadir Bakhsh Jamali \\ Department of Mechanical Engineering, Quaid-e-Awam \\ University of Engineering, Science and Technology, \\ Nawabshah, Sindh, Pakistan \\ qjamali@quest.edu.pk
}

\begin{abstract}
As the demand for concrete rises, the concrete materials demand increases. Aggregates occupy $75 \%$ of concrete. A vast amount of aggregates is utilized in concrete while aggregate natural resources are reducing. To overcome this problem, River Indus sand (RIS) and recycled concrete aggregate (RCA) were utilized as fine and coarse aggregate respectively. The aim of this experimental investigation is to evaluate the workability, and compressive and tensile strength of concrete utilizing RIS and RCA. Concrete samples of 1:2:4 proportions were cast, water cured for 7, 14, 21 and 28 days, and tested for compressive and tensile strength. The outcomes demonstrate that concrete possessed less workability when RIS and RCA were utilized. It was predicted that compressive strength of concrete would reduce up to $1.5 \%$ when $50 \%$ RIS and $50 \%$ RCA were utilized in concrete and $11.5 \%$ when natural aggregate was fully replaced by RIS and RCA, whereas the tensile strength decreased up to $1.60 \%$ when $50 \%$ by $12 \%$ respectively.
\end{abstract}

Keywords-compressive strength; split tensile strength; workability; River Indus sand (RIS); recycled concrete aggregates (RCA)

\section{INTRODUCTION}

Concrete is the one of the most utilizable products in construction manufacturing industry. Concrete has great durability, serviceability and availability compared to other building materials [1, 2]. Residential houses, skyscrapers, bridges, pavements and dams are mostly being constructed using concrete [3]. Nowadays it has become the major construction building material [4]. The main ingredients used to manufacture concrete are binder (cement), aggregates (coarse and fine), water and admixtures [5]. Aggregates are non-chemical reactive materials in concrete. They occupy 60-
$75 \%$ of the concrete's total volume. Their texture, shape and sizes play a vital role in fresh and hardened concrete properties [6-7]. In construction industry, the aggregates are mostly obtained from natural resources [8]. High energy is used to obtain these aggregates and natural resources are utilized [9]. Gradual depletion of natural resources has forced construction industry to focus more on sustainability and utilization of waste materials [10]. In this study, RIS and demolished concrete waste, commonly known as recycled concrete aggregates (RCA), were utilized and partially and fully replaced fine aggregates and coarse aggregates respectively. Workability, compressive and tensile strength of concrete were analyzed in context of conventional concrete.

\section{LITERATURE REVIEW}

Though concrete is considered as the backbone of any country's infrastructure $[11,12]$, the use of natural resources in the manufacturing of concrete has raised environmental concerns. To overcome such concerns, the performance of concrete by replacing sand and coarse aggregate with other alternative sources has been examined. Authors in [13] analyzed the experimental performance of concrete by partially replacing sand with foundry sand with various proportions of fine aggregates $(10 \%, 20 \%, 30 \%, 40 \%$ and $50 \%$ by mass $)$ at various curing ages ( 7 days, 14 days and 28 days). The conclusion confirmed that $30 \%$ replacement was optimum. Compressive upsurges decline beyond that. Authors in [14] observed the slump flow and hardened state strength performance of concrete at $10 \%, 20 \%, 30 \%, 40 \%$, and $50 \%$ partially replacement of foundry sand to natural sand. The results revealed that the slump flow of $30 \%$ replacement was satisfactory and the strength performance was boosted among 
the other proportions. Authors in [15] experimentally examined the strength (compressive, split tensile strength and flexural strength) behavior of concrete while utilizing foundry sand as fine aggregate replacement. Foundry sand was replaced at various fractions $0,15 \%, 25 \%$ and $35 \%$ with natural sand. The outcomes defined that the $25 \%$ replacement exhibited maximum strength among other percentages. RIS was used in [16] as fine aggregate replacement in concrete of various grades. Fine aggregates were fully replaced in M15, M20 and M25 grade concretes and their tensile strength was compared with concrete containing no replacement. It was determined that workability reduced significantly while the tensile strength was $1 \%$ to $2 \%$ lower than the conventional concrete's in all grades, suggesting that RIS would be utilized in order to conserve natural fine aggregates. Authors in [17] inspected the material and mechanical characteristics of concrete adding RCA as partially replacement of natural coarse aggregates at various fractions: $0 \%, 35 \%, 50 \%$ and $65 \%$. The outcomes revealed that the RCA has less specific gravity and high water absorption in context to natural aggregates. Also, compressive and flexural behavior was analyzed. The compressive and flexural strength reduced up to $35 \%$ compared to conventional concrete.

Authors in [18] conducted an experimental study on concrete incorporating rice husk ash as cement and RCA as coarse replacement. Concrete with full coarse aggregate replacement with RCA and with full coarse aggregate replacement with RCA along with $10 \%$ RHA as cement replacement was analyzed and compared with control concrete. It was determined that the workability reduced with the use of RCA and further declined when RHA was used. It was further noticed that $100 \%$ RCA concrete showed significantly lower compressive and tensile strength compared to control concrete. Interestingly the $10 \%$ RHA $+100 \%$ RCA concrete showed increase in strength, suggesting that incorporation of RCA can be beneficial if it is used along with other materials. Authors in [19] analyzed experimentally the performance of concrete using RCA as coarse aggregate replacement at 20\%, 40\%, $60 \%, 80 \%$ and $100 \%$. Mechanical and surface characteristics, permeability and greenhouse gases valuation were also evaluated at 7 and 28 days of curing. The results describe that by adopting RCA the mechanical performance was lower compared to conventional concrete's. Permeability was maximum when RCA was incorporated in concrete in terms of conventional concrete. Greenhouse gases investigation expressed that the $\mathrm{CO}_{2}$ emission of this $100 \%$ RCA mix was $24 \%$ lesser than the control mix. Based on the above literature review, in this study RIS was utilized as fine aggregate replacement whereas RCA was adopted as coarse aggregates.

\section{RESEARCH METHODOLOGY}

\section{A. Materials}

Cement from the brand Lucky, an ordinary Portland cement CEM I 42.5N that obeys ASTM C0150-04AE01, was chosen for this study. In this research two types of aggregates (aggregates obtained from hill and RCA) were utilized. The material properties of aggregates obtained from hill were: the fines modulus of coarse aggregates was $3.18 \%$, water absorption was $1.59 \%$, and the specific gravity was 2.58 whereas the RCA had fines modulus $2.91 \%$, water absorption $2.39 \%$ and specific gravity of 2.32 . Hill sand possessed fines modulus of $3.10 \%$, water absorption $1.2 \%$ and specific gravity of 2.46. And RSI had fines modulus $2.14 \%$, water absorption 3.62 and specific gravity 2.46 .

\section{B. Experimental Procedure and Mix Proportions}

The 1:2:4 mix design ratio for 3000 psi strength concrete was used for this study. Two different kinds of concrete mix were made, one was conventional concrete utilizing natural aggregates and the other was concrete incorporating RIS as fine aggregates and RCA as coarse aggregates. The aggregates were $50 \%$ partially and fully replaced with RIS and RCA as fine and coarse aggregates respectively. The concrete cubes were cast and tested for compressive strength at curing ages of 7, 14, 21 and 28 days and for the split tensile strength test the cylinders were cast for different curing ages 7, 14, 21 and 28 days. Concrete mixing was done by a semi-automatic rotary mixer. Slump flow of both concrete mixes was analyzed according to the method described in [20]. Compressive strength of both concretes was tested according to the overall method defined in [21] and split tensile strength was tested according to [22].

\section{RESULTS AND DISCUSSION}

\section{A. Workability}

To check the workability of concrete, ASTM C 143 was followed. The workability outcomes of both concretes are given in Table I showing that workability declines along with RIS and RCA percentage.

\section{TABLE I. WORKABILITY}

\begin{tabular}{|c|c|}
\hline Mixture & Slump Value (mm) \\
\hline Conventional concrete & 33.34 \\
\hline $50 \%$ RIS and $50 \%$ RCA concrete & 27.4 \\
\hline $100 \%$ RIS and $100 \%$ RCA concrete & 22.8 \\
\hline
\end{tabular}

\section{B. Compressive Strength}

To check the compressive strength, ASTM C39 was fallowed. The compressive strength outcomes are shown in Table II and illustrated in Figure 1. The results demonstrate that by utilizing RIS and RCA the strength is reduced because the interlocking between the particles is not as strong and in utilizing RIS because a huge number of clay particles are present reducing the cement chemical hydration.

TABLE II. AVERAGE COMPRESSIVE STRENGTH

\begin{tabular}{|c|c|c|c|c|}
\hline \multirow{2}{*}{ Mixture } & \multicolumn{4}{|c|}{ Compressive Strength (MPa) } \\
\cline { 2 - 6 } & 7 Days & 14 Days & 21 Days & 28 Days \\
\hline Conventional concrete & 14.21 & 18.36 & 20.18 & 21.09 \\
\hline $50 \%$ RIS and 50\% RCA concrete & 12.42 & 16.69 & 18.98 & 20.79 \\
\hline $100 \%$ RIS and $100 \%$ RCA concrete & 11.32 & 15.61 & 17.72 & 18.91 \\
\hline
\end{tabular}

At 7 days water curing, the compressive strength of $50 \%$ RIS and 50\% RCA concrete and RIS and RCA concrete, reduces by $14.41 \%$ and $25.53 \%$ respectively. At 14 days water curing, the compressive strength of 50\% RIS and 50\% RCA concrete and RIS and RCA concrete, reduces by $10 \%$ and $17.61 \%$ respectively. At 21 days water curing the compressive strength of $50 \%$ RIS and 50\% RCA concrete and RIS and RCA 
concrete, reduces by $6.32 \%$ and $13.88 \%$ respectively and at 28 days water curing the compressive strength of $50 \%$ RIS and $50 \%$ RCA concrete and RIS and RCA concrete, reduces up to $1.44 \%$ and $11.52 \%$ respectively.

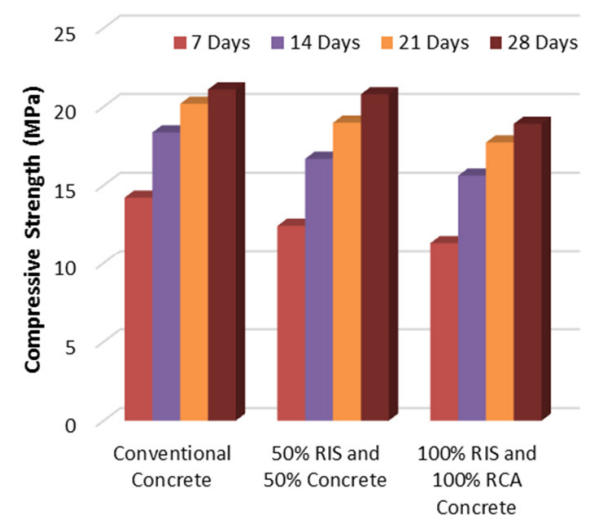

Fig. 1. Average compressive strength ss. curing age.

\section{Split Tensile Strength}

To check split tensile strength, ASTM C496 was fallowed. The split tensile strength test results are presented in Table III and illustrated in Figure 2. The outcomes describe that by adopting RIS and RCA the tensile strength is decreased because the RIS contains more clay particles causing the bonding between the particles to weaken while RCA are lighter than natural aggregates and the concrete becomes more brittle. Hence, while utilizing RIS and RCA, the split tensile strength is decreased.

TABLE III. AVERAGE SPLIT TENSILE STRENGTH

\begin{tabular}{|c|c|c|c|c|}
\hline \multirow{2}{*}{ Mixture } & \multicolumn{4}{|c|}{ Split Tensile Strength (MPa) } \\
\cline { 2 - 5 } & 7 Days & 14 Days & 21 Days & 28 Days \\
\hline Conventional concrete & 1.49 & 2.12 & 2.42 & 2.53 \\
\hline $50 \%$ RIS and 50\% RCA concrete & 1.34 & 1.84 & 2.28 & 2.49 \\
\hline $100 \%$ RIS and 100\% RCA concrete & 1.25 & 1.72 & 1.95 & 2.27 \\
\hline
\end{tabular}

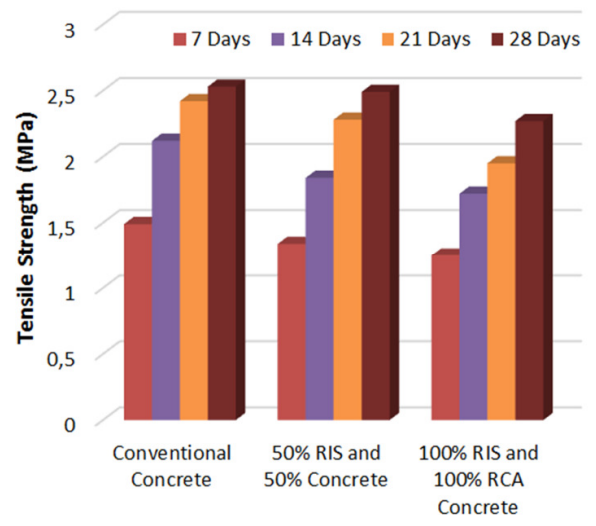

Fig. 2. Average tensile strength Vs. curing age.

At 7 days water curing, the tensile strength of $50 \%$ RIS and $50 \%$ RCA concrete and RIS and RCA concrete was reduced by $11.19 \%$ and $19.20 \%$ respectively, at 14 days curing it was reduced by $13.20 \%$ and $23.26 \%$ respectively, at 21 days by $6.14 \%$ and $24.10 \%$ and at 28 days it was reduced by $1.60 \%$ and $11.45 \%$ respectively.

\section{CONCLUSION}

It can be concluded that when 50\% RIS and 50\% RCA were utilized in concrete the slump value was less than conventional concrete's whereas when RIS and RCA fully replaced natural aggregates the slump value was even lower. For improvement in slump flow, certain chemical admixtures should be utilized. From the mechanical properties results, compressive strength of 50\% RIS and 50\% RCA concrete decreased up to $1.5 \%$ compared to conventional concrete at 28 days of curing. Concrete compressive strength was reduced up to $11.5 \%$ when RIS and RCA fully replaced natural aggregates at 28 days curing. Tensile strength decreased up to $1.60 \%$ compared to conventional concrete when 50\% RIS and 50\% RCA were utilized at 28 days curing. The concrete tensile strength reduced up to $12 \%$ compared to conventional concrete when RIS and RCA fully replaced natural aggregates at 28 days of curing.

\section{REFERENCES}

[1] E. Aprianti, "A huge number of artificial waste material can be supplementary cementitious material (SCM) for concrete production -a review part II", Journal of Cleaner Production, Vol. 142, No. 4, pp. 4178-4194, 2017

[2] Z. Li, "Introduction to Concrete" in: Advanced Concrete Technology, John Wiley and Sons, 2011

[3] A. A. Jhatial, S. Sohu, N. K. Bhatti, M. T. Lakhiar, R. Oad, "Effect of Steel Fibres on the Compressive and Flexural Strength of Concrete", International Journal of Advanced and Applied Sciences Vol. 5, No. 10, pp. $16-21,2018$

[4] M. T. Lakhiar, S. Sohu, I. A. Bhatti, N. K. Bhatti, S. A. Abbasi, M. Tarique, "Flexural Performance of Concrete Reinforced by Plastic Fibers", Engineering, Technology \& Applied Science Research, Vol. 8, No. 3, pp. 3041-3043, 2018

[5] A. M. Neville, Properties of Concrete, pp. 400-407, Prentice Hall, 2011

[6] C. S. Poon, Z. H. Shui, L. Lam, H. Fok, S. C. Kou, "Influence of Moisture States of Natural and Recycled Aggregates on the Slump and Compressive Strength of Concrete", Cement and Concrete Research, Vol. 34, No. 1, pp. 31-36, 2004

[7] A. Omoregie, O. E. Alutu, "The Influence of Fine Aggregate Combinations on Particle Size Distribution, Grading Parameter, and Compressive Strength of Sandcrete Blocks", Canadian Journal of Civil Engineering, Vol. 33, No. 10, pp. 1271-1278, 2006

[8] M. T. Lakhiar, N. Mohamad, S. Sohu, A. A. Jhatial, M. Oad, "Mechanical Properties of Concrete Containing River Indus Sand and Recyclable Concrete Aggregate", Civil Engineering Journal, Vol. 4, No. 8, pp. 1869-1876, 2018

[9] D. K. Bangwar, A. Saand, M. A. Keerio, M. A. Soomro, A. N. Laghari, "Replacement of Coarse Aggregate with Locally Available Brick Aggregate", Engineering, Technology \& Applied Science Research, Vol. 7, No. 6, pp. 2266-2267, 2017

[10] A. A. Jhatial, W. I. Goh, N. Mohamad, S. Sohu, M. T. Lakhiar, "Utilization of Palm Oil Fuel Ash and Eggshell Powder as Partial Cement Replacement - A Review", Civil Engineering Journal, Vol. 4, No. 8, pp. 1977-1984, 2018

[11] A. A. Jhatial, S. Sohu, M. T. Lakhiar, J. Shahzaib, A. A. Buriro, "Effectiveness of Locally Available Superplasticizers on the Workability and Strength of Concrete", Civil Engineering Journal, Vol. 4, No. 12, pp. 2919-2925, 2018

[12] A. Khitab, M. T. Arshad, F. M. Awan, I. Khan, "Development of an acid resistant concrete: a review", International Journal of Sustainable 
Construction Engineering and Technology, Vol. 4, No. 2, pp. 33-38, 2013

[13] A. D. Raval, A. Pamnani, A. I. Kachwala, "Foundry sand: utilization as a partial replacement of fine aggregate for establishing sustainable concrete", International Journal of Engineering Sciences \& Research Technology, Vol. 4, No. 1, pp. 308-311, 2015

[14] K. Amrutha, S. Adharsh, K. Ashirwad, K. Fareen, M. Najila, R. Praseedha, "Partial Replacement of Fine Aggregate by Used Foundry Sand in Concrete", International Research Journal of Engineering and Technology, Vol. 4, No. 3, pp. 165-169, 2017

[15] D. R. Bhimani, J. Pitroda, J. J. Bhavsar, "Used foundry sand: opportunities for development of ecofriendly low cost concrete", International Journal of Advanced Engineering Technology, Vol. 4, No. 1, pp. $63-66,2013$

[16] M. T. Lakhiar, N. Mohamad, M. A. B. Shaikh, A. A. Vighio, A. A. Jhatial, A. A. A. Samad, "Effect of River Indus Sand on Concrete Tensile Strength", Engineering, Technology \& Applied Science Research, Vol. 8, No. 2, pp. 2796-2798, 2018

[17] F. R. Salehlamein, M. Solikin, I. Sunarjono, "Effect of Recycled Coarse Aggregate on Concrete Properties", International Journal of Innovative Research in Science, Engineering and Technology", Vol. 4, No. 1, pp. 19060-19068, 2015

[18] N. Bheel, S. L. Meghwar, S. Sohu, A. R. Khoso, A. Kumar, Z. H. Shaikh, "Experimental Study on Recycled Concrete Aggregates with Rice Husk Ash as Partial Cement Replacement”, Civil Engineering Journal, Vol. 4, No. 10, pp. 2305-2314, 2018

[19] S. P. Yap, P. Z. C. Chen, Y. Goh, H. A. Ibrahim, K. H. Mo, C. W. Yuen, "Characterization of pervious concrete with blended natural aggregate and recycled concrete aggregates", Journal of Cleaner Production, Vol. 181, pp. 155-165, 2018

[20] ASTM, ASTM C143/C143M-15, Standard Test Method for Slump of Hydraulic-Cement Concrete), ASTM International

[21] ASTM, ASTM C39/C39M-18, Standard Test Method for Compressive Strength of Concrete, ASTM International

[22] ASTM , ASTM C496/C496M -17, Standard Test Method for Splitting Tensile Strength of Cylindrical Concrete Specimens, ASTM International 